\title{
The Origins of Autism
}

A review of: Ingram JL, Stodgell CJ, Hyman SL, et al. 2000 Discovery of allelic variants of HOXA1 and HOXB1: genetic susceptibility to autism spectrum disorders. Teratology 62:393-405

$\mathrm{T}$ HE TERM AUTISM spectrum disorders (ASDs) includes autism, pervasive developmental disorder, Asperger disorder and childhood disintegrative disorder. ASDs are characterized by impairments of social reciprocity, deficits in communication, and by the presence of restricted behaviors (1). The prevalence rate of ASDs is between 6-10 per 10,000 , representing an increase from previous estimates probably as a result of ascertainment bias (2). In terms of etiology it now seems clear that ASDs are the product of developmental brain abnormalities with a significant genetic influence. This stands in contrast to a history in the field of attributing "cold" parents and adverse social circumstances as causes of the disorders.

In terms of the neurobiology of ASDs, magnetic resonance imaging (MRI) and neuropathology studies have identified abnormalities in the hippocampal region and underdevelopment of the brainstem and cerebellum (3). These findings suggest that autism involves the abnormal development of a distributed neural network involving a number of regions of the brain. Studies attempting to correlate these findings with positron emission tomography (PET) metabolic studies have revealed low metabolic activity in frontal cortex and cerebellum (4). How these findings link to the abnormalities in communication, social skills, and behavior found in ASDs, however, remain unclear.

The genetic evidence in autism is compelling and comes from both twin studies and more extensive family studies (5). They show that the rate of autism is much greater among identical twins than fraternal twins, and among siblings of children with autism than in the general population. These rates, however,

\section{Mark L. Batshaw, AND \\ Kenneth E. Towbin}

are not as high as would be predicted by Mendelian genetics. This has led to the hypothesis that autism may be a contiguous gene disorder; i.e., the end product of a number of closely situated genes acting together (6). No specific gene for autism has been clearly identified to this point. Initial work pointing to the serotonin transporter gene or gamma-aminobutyric acid receptor subunit beta3 (GABRB3) has not held up on replication $(7,8)$. Other work points to chromosome $7(5), 13$ (5) and the q11-q13 region of 15 (5) as sites for further exploration of autism genes. A relatively increased prevalence of autistic spectrum disorders in persons with Fragile $\mathrm{X}$ and tuberous sclerosis (9Q34 and 16p13.3) (9) suggest other regions as well.

More recently, Rodier (10) has suggested an association of ASDs with defects in the gene coding for HOXA1 that affects the transcription of other genes early in embryonic development. Prior work placed the HOXA1 coding region on chromosome 7, and a detailed screening of 75 families suggests that a variation on the long arm of chromosome 7 may be important in determining autism (11) and this same area surfaced in a genome scan of 90 multiplex families (5). Rodier's group chose to explore this gene because mice with null mutations had abnormal hindbrain development and phenotypic features suggestive of autism. In the paper reviewed here (12) Ingram and colleagues sequenced regions of genomic DNA of patients with ASDs and detected a substitution variant at HOXA1 and an insertion variant of HOXB1, both in coding regions of the genes. Fifty-seven individuals ascertained for a diagnosis of an ASD, along with 166 of their relatives, were typed for these variants. Two non-ASD populations were also typed, and the frequency of the alleles was determined in all groups. They found that the frequency of the HOXA1 variant was $10-25 \%$ in non ASD family controls of European or African origin but approximately $40 \%$ in the ASD families, suggesting that this alteration may predispose them to ASDs. A significant association was not found with HOXB1. While the association does not define the HOXA1 gene a cause of ASDs, this study represents another step in our understanding of these complex disorders. It also points to the brainstem as potentially playing a major role in the symptom complex that defines these disorders.

1. Rapin I 1997 Autism. N Engl J Med 337(2): 97-104

2. Fombonne E 1999 The epidemiology of autism: a review. Psychol Med 29(4): 769-786

3. Tager-Flusberg H, Joseph R, Folstein S 2001 Current direction in research on autism. Ment Retard Dev Disabil Res Rev 7:21-29

4. Rumsey, J M, Ernst M 2000 Functional neuroimaging of autistic disorders. Ment Retard Dev Disabil Res Rev 6(3): 171-179

5. Lamb JA, More J, Bailey A, Monaco AP 2000 Autism: recent molecular genetic advances. Hum Mol Genet 9:861-868

6. Rutter, M. 2000 Genetic studies of autism: from the 1970s into the millennium. J Abnorm Child Psychol 28(1): 3-14

7. Maestrini E, Lai C, Marlow A, Matthews N, Wallace S, Bailey A, Cook EH, Weeks DE, Monaco AP 1999 Serotonin transporter (5-HTT) and gamma-aminobutyric acid receptor subunit beta3 (GABRB3) gene plymorphisms are not associated with autism in the IMGSA families. The International Molecular Genetic Study of Autism Consortium. Am J Med Genet 88:492-496

8. Cook EH Jr, Courchesne R, Lord C, Cox N J, Yan S, Lincoln A, Haas R, Courchesne E, Leventhal BL 1997 Evidence of linkage between the serotonin transporter and autistic disorder. Mol Psychiatry 2(3): $247-250$

9. Cheadle JP, Reeve MP, Sampson JR, Kwiatkowski DJ 2000 Molecular genetic advances in tuberous sclerosis. Hum Genet 107:97-114

10. Rodier PM 2000 The early origins of autism. Sci Am 282(2): 56-63 
11. Wassick T.H., Piven J 2000 The Molecular Genetics of Autism. Curr Psychiatry Rep 2(2): 170-175.

12. Ingram JL, Stodgell CJ, Hyman SL, Figlewicz DA, Weitkamp LR, Rodier RM 2000 Discovery of allelic variants of HOXA1 and HOXB1: genetic susceptibility to autism spectrum disorders. Teratology 62:393-40520
Mark L. Batshaw

Children's National Medical Center

George Washington University School of Medicine and Health Sciences

111 Michigan Avenue NW

Washington, DC 20008, U.S.A.
Kenneth E. Towbin

National Institute of Mental Health

9000 Rockville Pike

Building 10, Room 3S 228 A

Bethesda, MD 20892, U.S.A. 